\title{
Molecular Docking Study of Active Compunds in Ginger as Inhibitor Against Covid-19
}

\author{
Priyagung Dhemi Widiakongko ${ }^{1, *}$ Darmawan Alisaputra ${ }^{1}$
}

\author{
Tawatchai Kangkamano ${ }^{2}$ \\ ${ }^{1}$ Department of Chemistry UIN Sunan Kalijaga Yogyakarta, Indonesia \\ ${ }^{2}$ Department of Chemistry Thaksin University Thailand \\ "Corresponding author. Email: priyagung.widiakongko@uin-suka.ac.id
}

\begin{abstract}
Molecular docking of the active compounds of ginger (Zingiber officinale) has been successfully carried out. This study aims to examine the potential inhibitor of ginger's main active compounds in spike proteins on the COVID19 virus. A total of 4 main active compounds in ginger, namely alpha-Curcumene, alpha-Farnesene, betaSesquiphellandrene, and Zingiberen, were studied individually for molecular docking of spike proteins in the Covid-19 virus. The results obtained were compared with the native ligand 7a94 extracted from the protein database. Molecular docking was also carried out on the combination of these active compounds. The results of this docking study indicate that $\alpha$-Curcumene, $\alpha$-Farnesene, $\beta$-Sesquiphellandrene, and Zingiberen have a higher affinity than the native ligands. Combinational docking $\alpha$-Curcumene, $\alpha$-Farnesene, $\beta$-Sesquiphellandrene, and Zingiberen against spike protein COVID-19 virus has a better affinity of $-59.567 \mathrm{kcal}$ better than native ligands of $-50.053 \mathrm{kcal}$. The results of this study indicate that the main active compounds in ginger and their combination has the potential to inhibit the COVID-19 virus activity in the human body.
\end{abstract}

Keywords: COVID-19 virus, ginger, active compounds, molecular docking.

\section{INTRODUCTION}

Drug treatment therapy for COVID-19 (Corona Virus Disease-19) continues to be developed to date. The disease is caused by an infection with SARS CoV2 (Severe Acute Respiratory System-Corona Virus), which began to spread at the end of 2019 [1]. Several commercial drugs that are claimed to be able to treat SARS CoV-2 infection are Ibuprofen and Cortisone, but recent research shows that these two drugs do not have any activity against the virus that causes COVID19 [2]. Thus, the discovery of drugs for this disease is very urgent to continue to be developed so that the pandemic condition ends soon.

Several drug discoveries for COVID-19 have been reported. These drugs have a mechanism that inhibits the protein RNA-dependent RNA polymerase (RdRP) [3], [4] so that the replication of the virus in the human body can be stopped. Drugs that work through this mechanism are Remdesivir and Ribavirin [4]. In addition, other drug mechanisms deactivate the structure of the virus through the inhibition of spike proteins [4], such as chloroquine and mycophenolic acid [4]. The role of Artificial Intelligence is also currently involved in determining the best medicine [5], [6]. Some of these studies have yielded good results in the development of drug therapy for CoVID19. However, research on potential drugs derived from natural ingredients has not been widely reported. Thus, the discovery of potential drugs from natural ingredients has a great opportunity to be developed.

Ginger is a natural plant that has many active compounds that have medicinal properties. The main active compounds in ginger include alpha-curcumene, alpha-Farnesene, beta-Sesquiphellandrene, and Zingiberen[7], [8]. The combination of ginger's active compounds has been reported to be therapeutic for human respiratory diseases [9], chikungunya [10], and herpes simplex [11], all of which are caused by viral infections. The combination of these active compounds has been clinically proven to inhibit the 
activity of viruses that infect the human body. The active compound in ginger inhibits the virus by blocking the active site of the virus [10]. With this potential, the active compounds in ginger can be studied as an alternative to drug therapy for COVID19 from natural ingredients.

The discovery of new drug compounds can now be assisted using a computational chemical device, namely molecular docking [12]. Molecular docking is the process of tethering a ligand compound in the form of a drug molecule to a protein molecule from the target [13]. Molecular docking studies can help to generate data on interactions between drug compounds and target proteins through the docking score. The more negative the docking score, the higher the ligand's binding affinity to the target molecule [14]-[18].

Several researchers have reported studies of molecular docking of SARS CoV-2. Synthetic drugs that have been circulating in general and have antiviral potentials such as remdesivir, ribavirin, fapivarin, chloroquine, and hydroxychloroquine have good binding affinity values for SARS CoV-2 [12]. The target molecules that have been tested are also various, including ACE-2 [13], 6LU7 and 6CS2, which are spike proteins from SARS CoV-2 [12]. The docking calculation has also been developed in the study of supercomputers to obtain more precise calculations [19].

From the previous studies that have been done, the opportunity to conduct a molecular docking study of drug compounds that have antiviral potential is widely open, especially for natural ingredients such as ginger. Ginger which has been proven to have antiviral activity against several diseases also needs to be studied for molecular docking of the SARS CoV-2 virus, especially its 4 main compounds. In addition, for improving the binding affinity of the 4 main active compounds in ginger, a combination docking method or multiple ligand docking [20] needs to be applied. Molecular docking studies using PLANTS application on the active compounds of ginger gave results in the form of docking scores and amino acid sites that interact with these compounds. These results can be used to determine the potential of ginger as a natural ingredient that has antiviral activity and their potential to be developed as natural alternative drugs for CoVID-19.

\section{RESEARCH METHODS}

The research design used in this study was an exploratory study using the in silico method of marker compounds from 4 derivatives of ginger compounds against spike coronavirus (7a49), namely alphaCurcumene, alpha-Farnesene, betaSesquiphellandrene, and Zingiberen using the PLANTS molecular docking application.

\subsection{Test Protein Preparation}

The protein to be used as the test receptor was downloaded from the official website of the protein data bank (www.rscb.org) in ".pdb" format.

\subsection{In Silico Preparation and Test}

\subsubsection{Preparation of Test Protein and Native Ligand}

The test protein and native ligand (NAG 1301) were prepared using the YASARA application. The test protein in virtual form with ".pdb" format is opened. Then chain A is selected, and the other chains are removed. The native ligands, residues such as $\mathrm{H} 2 \mathrm{O}$ compounds, and hydrogen ions are also removed. The prepared protein is stored in ".mol2" format. The native ligand preparation of the test protein was carried out by opening the protein file on the new YASARA page. After that, all residues were removed except the native ligand (NAG 1301). The native ligand file is saved in ".mol2" format.

\subsubsection{Ligand preparation}

Ligand preparation was carried out using the Marvin Sketch application. In the validation test, the ligand file to be prepared was the native ligand made from YASARA. The ligand file is opened and then arranged in 2D. The ligands that have been formed were conditioned at $\mathrm{pH} 7.4$ to match the $\mathrm{pH}$ conditions of human body fluids and stored in ".mrv" format. The ".mrv" file re-opened on a new page of Marvin Sketch, and ten conformational ligands are made to be tested. The ligand conformation file is saved in ".mol2" format.

\subsubsection{Running the Molecular Tethering} Process

Running the PLANTS application must use the cmd application. After the protein file, native ligand, and ligand to be tested have been prepared, the supporting file for PLANTS is prepared, namely the "plantsconfig" file. This "plantsconfig" file is used as a container to hold protein files, native ligands, and ligands for the PLANTS application to run. 


\subsubsection{Protein Validation Process}

After obtaining the anchoring score, the ligand value conformation file is retrieved from the results folder. After that, the molecular docking method was validated by calculating the Root Mean Square Deviation (RMSD) value. YASARA application is used to measure the value of RMSD. The way to measure RMSD with YASARA is to open the native ligand file and then overlap it with the best file from the tethering result. Then by running the function "Analyze > RMSD of .." on YASARA, you can get the RMSD value of the protein binding with the native ligand.

\subsubsection{In Silico Marker Compound Test}

After obtaining the RMSD value, an in silico test was carried out on the marker compounds. The marker compound has been downloaded from the PubChem website (pubchem.ncbi.nlm.nih.gov) in "xml" format and converted into "cml" format using the Open Babel GUI application. The marker compound was then prepared using the Marvin Sketch application, and the processing steps were the same as for the RMSD measurement. After that, all marker compounds were tested in silico using the PLANTS application. Subsequently, an in silico test was conducted on Chloroquine and Remdesivir compounds to compare the docking scores.

\subsection{Combination Docking Test}

\subsubsection{Combination Docking Test Preparation}

Three new combination proteins were created using the YASARA application. The results of the in silico test of marker compounds are ordered from the highest anchoring score to the lowest score. The first test protein was made by tethering the old test protein with the marker compound with the highest score. Then, the second test protein was made by tethering the old test protein with two marker compounds with the highest score. Furthermore, the third test protein was made by tethering the old test protein with three marker compounds with the highest score.

\subsubsection{Combination In Silico Docking Test}

The in silico test using the PLANTS application is done after obtaining three new test protein. The first test protein was attached to the marker compound with the second-highest score. Then, the second test protein was tethered with a marker compound with the thirdhighest score. Furthermore, the third test protein was attached to the marker compound with the lowest score.

\subsubsection{Docking Result Visualization}

The process of visualizing the docking results can be done with the Biovia Discovery Studio application. The visualization process is selected by tethering the lowest docking result with the test protein and then saving it in ".pdb" format. The visualization results were then analyzed to know the position and description of the protein binding with each tested ligand.

\section{DISCUSSION}

The validation of the molecular docking method is an important step in the next molecular docking. This process is carried out by re-docking the native ligand to the SARS CoV-2 spike protein 7a49. The RMSD results generated from this validation method must have a value $\leq 2 \AA$ [21]. The RMDS of docking validation against native ligands in this study was $1.5786 \AA$. These results indicate that the method used in molecular docking in this study is validated. The value of the docking score, interaction, and RMSD between the SARS-CoV-2 spike protein and the native ligand is provided in Table 1 , while the visualization of molecular interaction of $7 \mathrm{a} 49$ protein spike with native ligand (NAG 1301) showed in Figure 1.

Table 1. Docing score, interactions, and RMSD SARS $\mathrm{CoV}-2$ spike protein with the native ligand (NAG 1301)

\begin{tabular}{|c|c|c|c|c|}
\hline \multirow{2}{*}{$\begin{array}{l}\text { Compoun } \\
\text { d }\end{array}$} & \multirow{2}{*}{$\begin{array}{l}\text { Dockin } \\
\text { g Score } \\
\text { (kcal) }\end{array}$} & \multicolumn{2}{|c|}{ Interactions } & \multirow{2}{*}{$\begin{array}{l}\text { RMS } \\
\text { D (̊) }\end{array}$} \\
\hline & & $\begin{array}{l}\text { Van der } \\
\text { waals }\end{array}$ & $\begin{array}{l}\text { Unfavorabl } \\
\text { e bump }\end{array}$ & \\
\hline $\begin{array}{l}\text { Native } \\
\text { ligand } \\
\text { (NAG } \\
1301 \text { ) }\end{array}$ & -50.053 & $\begin{array}{l}\text { THR302 } \\
\text { THR315 } \\
\text { ASN317 }\end{array}$ & SER316 & 1.5786 \\
\hline
\end{tabular}

The native ligand interacted with protein $7 \mathrm{a} 49$ of the SARS CoV-2 spike and has an unfavorable bump bond with SER316 and a van der Waals bond with three amino acids, namely THR302, THR315, dan ASN317. Visualization of the interactions of the native ligand is available in Figure 1. 


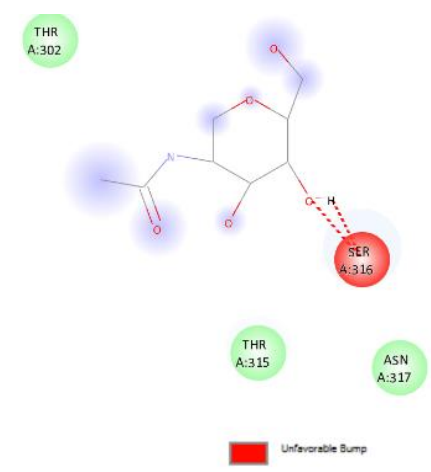

Figure 1 Visualization of molecular interaction of $7 \mathrm{a} 49$ protein spike with native ligand (NAG 1301)

Molecular docking was carried out on four main active compounds in ginger, namely alphaCurcumene, alpha-Farnesene, betaSesquiphellandrene, and Zingiberen. The result obtained is the docking score representing the binding affinity of protein $7 \mathrm{a} 49$ to the test compound. The lower the binding affinity or docking score of a compound, the better the interaction with protein $7 \mathrm{a} 49$.

Table 2. Docing score and interaction SARS CoV-2 spike protein with 4 ginger compounds

\begin{tabular}{|c|c|c|c|c|}
\hline \multirow[b]{2}{*}{ Compound } & \multirow{2}{*}{$\begin{array}{l}\text { Docking } \\
\text { Score } \\
\text { (kcal) }\end{array}$} & \multicolumn{3}{|l|}{ Interactions } \\
\hline & & $\begin{array}{l}\text { Van der } \\
\text { waals }\end{array}$ & & \\
\hline $\begin{array}{l}\text { alpha- } \\
\text { Curcumene }\end{array}$ & -54.124 & $\begin{array}{l}\text { THR302, } \\
\text { GLU298, } \\
\text { ASN317, } \\
\text { GLN314, } \\
\text { SER316 }\end{array}$ & - & THR315 \\
\hline THR315 & - & $\begin{array}{l}\text { THR302, } \\
\text { GLU298, } \\
\text { ASN317, } \\
\text { GLN314, } \\
\text { SER317 }\end{array}$ & $\begin{array}{l}- \\
57.795\end{array}$ & alpha-Farnesene \\
\hline THR315 & - & $\begin{array}{l}\text { THR302, } \\
\text { GLU298, } \\
\text { ASN317, } \\
\text { GLN314, } \\
\text { SER318 }\end{array}$ & $\begin{array}{l}- \\
55.593\end{array}$ & $\begin{array}{l}\text { beta- } \\
\text { Sesquiphellandrene }\end{array}$ \\
\hline $\begin{array}{l}\text { THR315, } \\
\text { SER316, } \\
\text { THR302, } \\
\text { GLU298, } \\
\text { TRP633 }\end{array}$ & VAL595 & $\begin{array}{l}\text { ARG319, } \\
\text { ASN317, } \\
\text { THR299, } \\
\text { GLN314, } \\
\text { VAL597, } \\
\text { SER596, } \\
\text { PRO295, } \\
\text { ALA292 }\end{array}$ & $\begin{array}{l}- \\
59.598\end{array}$ & Zingiberen \\
\hline
\end{tabular}

The docking score for each compound from Table 2 was $-54.124 \mathrm{kcal}$ for alpha curcumene, $-57.795 \mathrm{kcal}$ for alpha-Farnesene, $-55.593 \mathrm{kcal}$ for betaSesquiphellandrene, and $-59.598 \mathrm{kcal}$ for Zingiberene. The docking score of these four compounds was better than the docking score of the native ligand, which was $-50,0526 \mathrm{kcal}$.
Table 3. Docing score and interaction SARS CoV-2 spike protein with chloroquine and remdesivir

\begin{tabular}{|l|l|}
\hline Compound & Docking Score (kcal) \\
\hline Chloroquine & -62.056 \\
\hline Remdesivir & -84.528 \\
\hline
\end{tabular}

However, the docking scores of the four compounds still had lower value than currently commercialized as SARS CoV-2 drugs, namely Chloroquine and Remdesivir. As shown in the Table 3 , the docking score for Chloroquine was $-62.056 \mathrm{kcal}$ and for Remdesivir was $-84.528 \mathrm{kcal}$. However, Zingiberene compounds each have a docking score close to the drug compound Chloroquine. This indicates that Zingiberene compounds in ginger also has potential as a drug against SARS CoV-2.

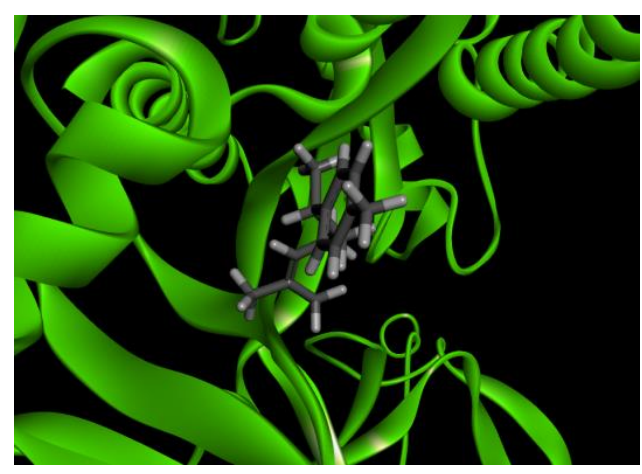

(a)

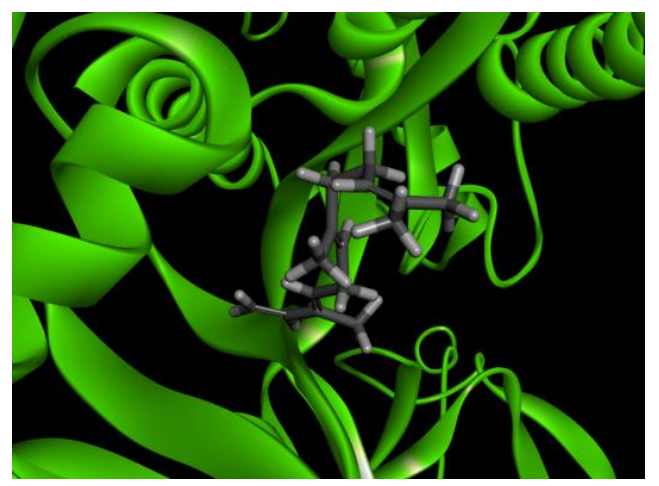

(b) 


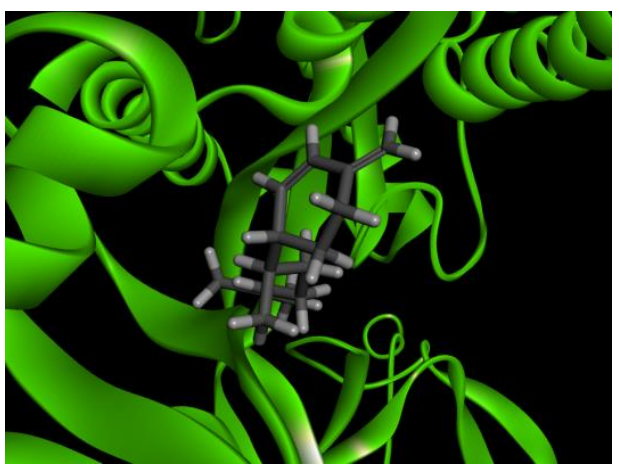

(c)

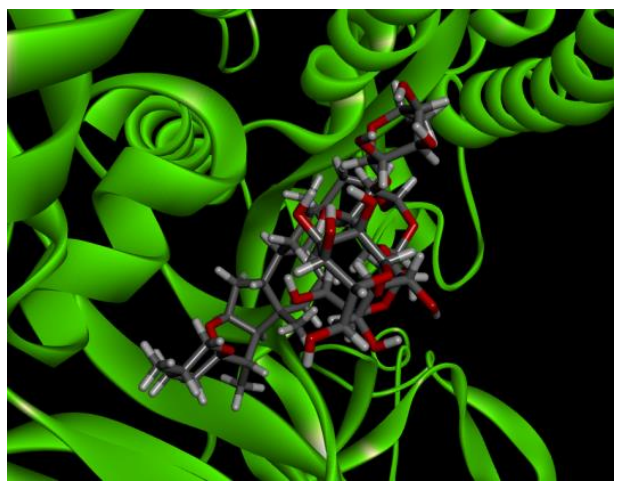

(d)

Figure $23 \mathrm{D}$ visualization of molecular interaction of 7 a49 protein spike with alpha-Curcumene (a), alphaFarnesene (b), beta-Sesquiphellandrene (c), Zingiberen (d).

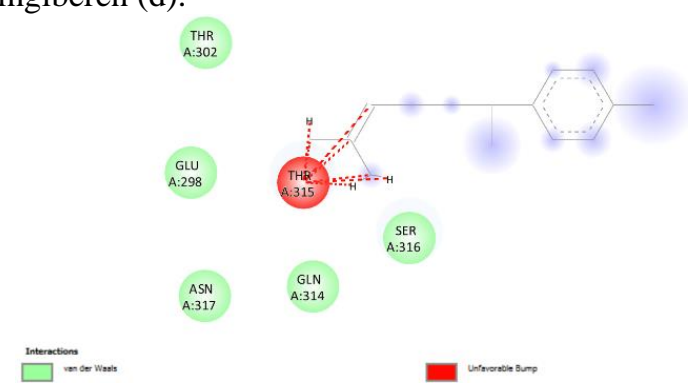

(a)

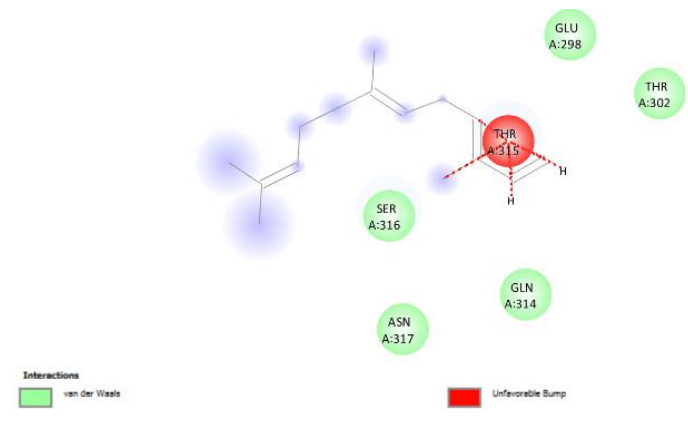

(b)

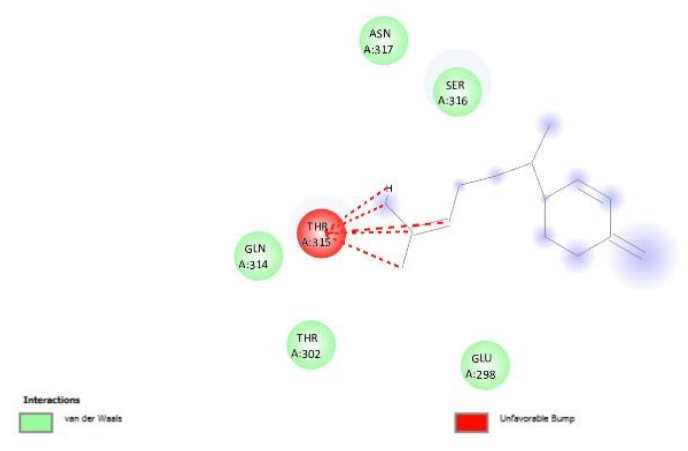

(c)

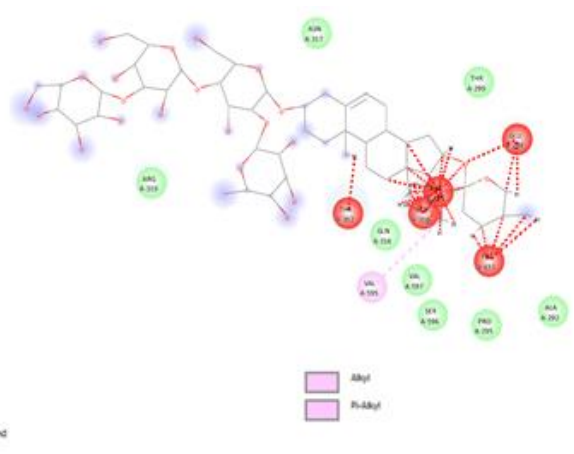

(d)

Figure 3 Visualization of molecular interaction of 7 a49 protein spike with alpha-Curcumene (a), alphaFarnesene (b), beta-Sesquiphellandrene (c), Zingiberen (d).

Visualization of the interactions of the four test compounds is showed in Figure 3. The four compounds interacted with van der Waals binding with protein $7 \mathrm{a} 49$ of the SARS CoV-2 spike. All four of them also have an unfavorable bump which is an interaction that occurs due to the steric effect of the compound [22], [23]. Alpha-Curcumene has an unfavorable bump bond with THR315 and a van der Waals bond with five amino acids, namely THR302, GLU298, ASN317, GLN314, and SER316., as well as alpha-Farnesene and beta-Sesquiphelandrene, which interact with the same amino acid as alphaCurcumene.

Different bonds are formed by the interaction between Zingiberene and protein 7a49. Zingiberen has 5 unfavorable bump bonds with THR315, SER316, THR302, GLU298 and TRP633, alkyl bonds with VAL595, and van der Waals bonds with 8 amino acids, namely ARG319, ASN317, THR299, GLN314, VAL597, SER596, PRO292, and ALA9. The various bonds formed by Zingiberene and protein $7 \mathrm{a} 49$ caused the docking score to be the lowest among the other 4 active compounds. In addition, the structure of Zingiberene is larger than other main active 
components of ginger, so Zingiberene has more interactions with protein $7 \mathrm{a} 49$.

The results were then obtained to become a reference in making a combination docking test for 4 ginger compounds at once. The docking test of the combination of 4 active compounds was carried out to determine its interaction of the combination of active compounds in ginger with spike protein $7 \mathrm{a} 49$. The value of the docking score between the SARS CoV-2 spike protein and the combination compound provided in Table 4.

Table 4. Docing score and interaction SARS CoV-2 spike protein with combinational ginger compounds

\begin{tabular}{|c|c|c|c|c|}
\hline \multirow{2}{*}{ Compound } & \multirow{2}{*}{$\begin{array}{l}\text { Dockin } \\
\text { g Score } \\
\text { (kcal) }\end{array}$} & \multicolumn{3}{|c|}{ Interactions } \\
\hline & & $\begin{array}{l}\text { Van der } \\
\text { waals }\end{array}$ & Alkyl & $\begin{array}{l}\text { Unfavora } \\
\text { ble bump }\end{array}$ \\
\hline $\begin{array}{l}\text { alpha- } \\
\text { Curcumene } \\
\text { and alpha- } \\
\text { Farnesene }\end{array}$ & -55.556 & $\begin{array}{l}\text { THR302, } \\
\text { GLU298, } \\
\text { ASN317, } \\
\text { GLN314, } \\
\text { SER316 }\end{array}$ & - & THR315 \\
\hline $\begin{array}{l}\text { alpha- } \\
\text { Curcumene, } \\
\text { alpha- } \\
\text { Farnesene, } \\
\text { and beta- } \\
\text { Sesquiphella } \\
\text { ndrene }\end{array}$ & -57.863 & $\begin{array}{l}\text { THR302, } \\
\text { GLU298, } \\
\text { ASN317, } \\
\text { GLN314, } \\
\text { SER316 }\end{array}$ & - & THR315 \\
\hline $\begin{array}{l}\text { alpha- } \\
\text { Curcumene, } \\
\text { alpha- } \\
\text { Farnesene, } \\
\text { beta- } \\
\text { Sesquiphella } \\
\text { ndrene, and } \\
\text { Zingiberen }\end{array}$ & -59.567 & $\begin{array}{l}\text { ARG319, } \\
\text { ASN317, } \\
\text { THR299, } \\
\text { GLN314, } \\
\text { VAL597, } \\
\text { SER596, } \\
\text { PRO295, } \\
\text { CYS291 }\end{array}$ & $\begin{array}{l}\text { VAL } \\
595, \\
\text { ALA } \\
292\end{array}$ & $\begin{array}{l}\text { THR315, } \\
\text { SER316, } \\
\text { THR302, } \\
\text { GLU298, } \\
\text { TRP633 }\end{array}$ \\
\hline
\end{tabular}

The docking score of the combination of 4 active compounds in ginger is $-59.567 \mathrm{kcal}$. This value is similar to the docking score for Zingiberene and close to the docking score for Chloroquine and Remdesivir.

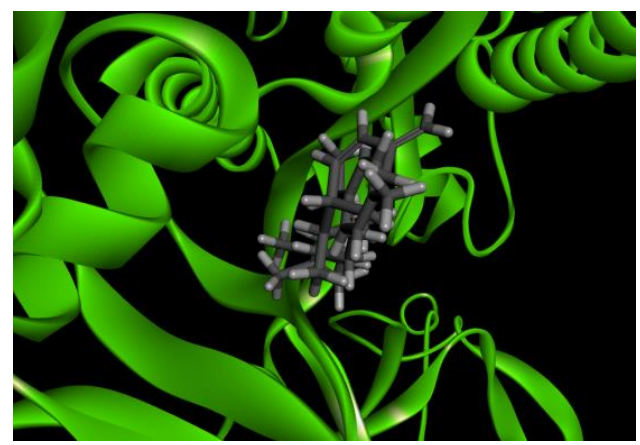

(a)

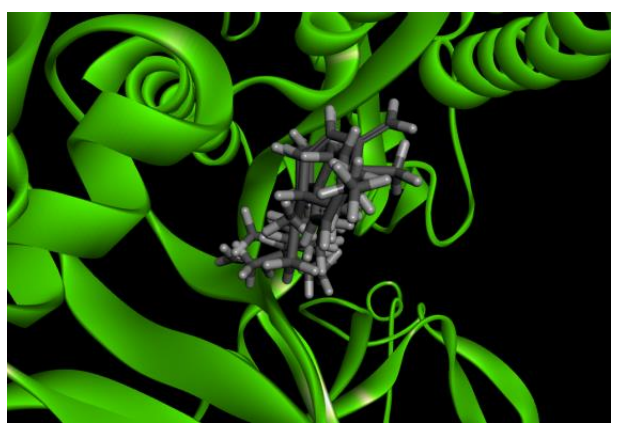

(b)

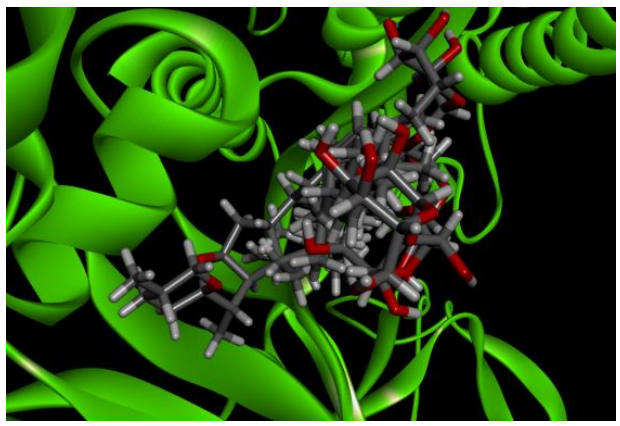

(c)

Figure 4 3D visualization of molecular interaction of 7a49 protein spike with docking combination alphaCurcumene and beta-Sesquiphellandrene (a), alphaCurcumene, beta-Sesquiphellandrene, and alphaFarnesene (b), alpha-Curcumene, betaSesquiphellandrene, alpha-Farnesene, and Zingiberen (c).

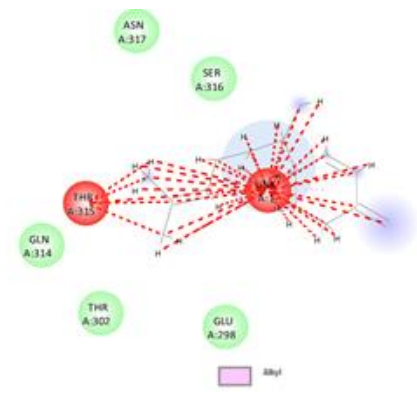

(a)

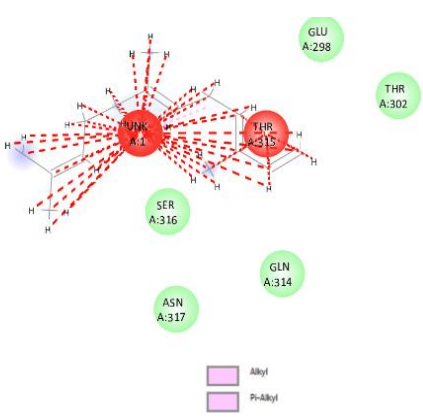

(b) 


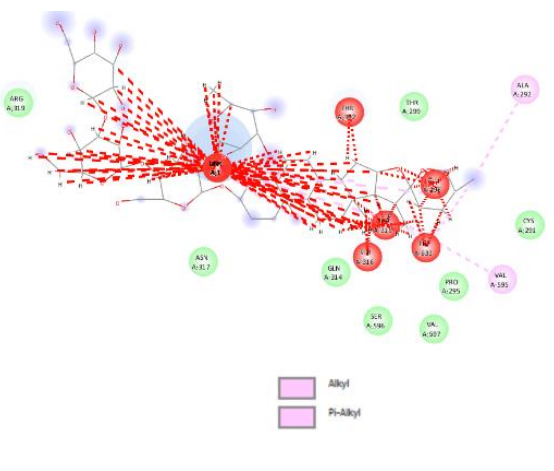

(c)

Figure 5. Visualization of molecular interaction of 7 a49 protein spike with docking combination alphaCurcumene and beta-Sesquiphellandrene (a), alphaCurcumene, beta-Sesquiphellandrene, and alphaFarnesene (b), alpha-Curcumene, betaSesquiphellandrene, alpha-Farnesene, and Zingiberen (c).

The molecular interactions between the SARS CoV-2 spike protein and the combination of 4 ginger compounds can be seen in Figure 5. The combination of alpha-Curcumene and beta-Sesquiphellandrene has an unfavorable bump bond between these ligands and with THR315, and also has van der Waals bonds with 5 acids. Amino acids, namely THR302, GLU298, ASN317, GLN314, and SER316. The combination of alpha-Curcumene, beta-Sesquiphellandrene, and alpha-Farnesene has an unfavorable bump bond between these ligands and with THR315, and also has van der Waals bonds with 5 amino acids, namely THR302, GLU298, ASN317, GLN314, and SER316. While the combination of alpha-Curcumene, betaSesquiphellandrene, alpha-Farnesene, and Zingiberen has an unfavorable bump bond between these ligands and 5 unfavorable bump bonds with THR315, SER316, THR302, GLU 298 and TRP633, 2 alkyl bonds with VAL595 and ALA292, as well as van der Waals with 8 amino acids, namely ARG319, ASN317, THR299, GLN314, VAL597, SER596, PRO295, and CYS291.

The interaction between the native ligand and all test ligands was almost similar, where the native ligand interacted with the 4 amino acids THR302, THR315, ASN317, SER316 from protein $7 \mathrm{a} 49$. Meanwhile, each test ligand also interacted with these 4 amino acids. This indicates that each test ligand can increase the position of the native ligand if it interacts with the $7 \mathrm{a} 49$ protein.

The interactions that occur from the combination of active compounds in ginger are more than those of individual active compounds. However, the combined docking score results have not shown better results than the individual docking scores. This shows that the interaction between the combination of 4 active compounds in ginger has a constructive bond with protein, as evidenced by more van der Waals bonds, but there is a destructive interaction as evidenced by more unfavorable bump bonds [23], [24]. Studies on the arrangement and coordination of the four active compounds in ginger against $7 \mathrm{a} 49$ protein are needed in the future to provide more representative results.

\section{CONCLUTION}

The results of this study indicate that the main active compounds in the ginger and their combination has the potential to inhibit the activity of the COVID19 virus in the human body because of the better affinity than native ligands.

\section{REFERENCES}

[1] L. Wang, Y. Wang, D. Ye, and Q. Liu, "Review of the 2019 novel coronavirus (SARS-CoV-2) based on current evidence," Int. J. Antimicrob. Agents, vol. 55, no. 6, p. 105948, 2020, doi: 10.1016/j.ijantimicag.2020.105948.

[2] G. A. Fitzgerald, "Misguided drug advice for COVID-19 permanently ban wildlife consumption wildlife consumption ban is insufficient," Science (80-. )., vol. 367, no. 6485, p. $1434,2020$.

[3] Y. Jiang, W. Yin, and H. E. Xu, "RNA-dependent RNA polymerase: Structure, mechanism, and drug discovery for COVID-19," Biochem. Biophys. Res. Commun., vol. 538, pp. 47-53, 2021, doi: 10.1016/j.bbrc.2020.08.116.

[4] K. Mohamed, N. Yazdanpanah, A. Saghazadeh, and N. Rezaei, "Computational drug discovery and repurposing for the treatment of COVID-19: A systematic review," Bioorg. Chem., vol. 106, no. October 2020, p. 104490, 2021, doi: 10.1016/j.bioorg.2020.104490.

[5] S. Mohanty, M. Harun AI Rashid, M. Mridul, C. Mohanty, and S. Swayamsiddha, "Application of Artificial Intelligence in COVID-19 drug repurposing," Diabetes Metab. Syndr. Clin. Res. Rev., vol. 14, no. 5, pp. 1027-1031, 2020, doi: 10.1016/j.dsx.2020.06.068.

[6] A. Keshavarzi Arshadi et al., "Artificial Intelligence for COVID-19 Drug Discovery and Vaccine Development," Front. Artif. Intell., vol. 3, no. August, pp. 1-13, 2020, doi: 10.3389/frai.2020.00065. 
[7] N. Azizah, E. Filaila, S. Salahuddin, E. Agustian, A. Sulaswatty, and N. Artanti, "Antibacterial and Antioxidant activities of Indonesian ginger (jahe emprit) essential oil extracted by hydrodistillation," J. Kim. Terap. Indones., vol. 20, no. 2, pp. 90-96, 2019, doi: 10.14203/jkti.v20i2.401.

[8] H. H. A. El-baky, R. S. Farag, and M. a Saleh, "Characterization of antioxidant and antimicrobial compounds of cinnamon and ginger essential oils," African J. Biochem. Res., vol. 4, no. 6, pp. 167-174, 2010.

[9] J. S. Chang, K. C. Wang, C. F. Yeh, D. E. Shieh, and L. C. Chiang, "Fresh ginger (Zingiber officinale) has anti-viral activity against human respiratory syncytial virus in human respiratory tract cell lines," J. Ethnopharmacol., vol. 145, no. 1, pp. 146-151, 2013, doi: 10.1016/j.jep.2012.10.043.

[10] S. Kaushik, G. Jangra, V. Kundu, J. P. Yadav, and S. Kaushik, "Anti-viral activity of Zingiber officinale (Ginger) ingredients against the Chikungunya virus," VirusDisease, vol. 31, no. 3, pp. 270-276, 2020, doi: 10.1007/s13337-02000584-0.

[11]P. Schnitzler, C. Koch, and J. Reichling, "Susceptibility of drug-resistant clinical herpes simplex virus type 1 strains to essential oils of ginger, thyme, hyssop, and sandalwood," Antimicrob. Agents Chemother., vol. 51, no. 5, pp. 1859-1862, 2007, doi: 10.1128/AAC.0042606.

[12] R. R. Narkhede, R. S. Cheke, J. P. Ambhore, and S. D. Shinde, "The Molecular Docking Study of Potential Drug Candidates Showing AntiCOVID-19 Activity by Exploring of Therapeutic Targets of SARS-CoV-2," Eurasian J. Med. Oncol., vol. 4, no. 3, pp. 185-195, 2020, doi: 10.14744/ejmo.2020.31503.

[13] C. N. Cavasotto and J. I. Di Filippo, "In silico Drug Repurposing for COVID-19: Targeting SARS-CoV-2 Proteins through Docking and Consensus Ranking," Mol. Inform., vol. 40, no. 1, 2021, doi: 10.1002/minf.202000115.

[14] J. Lan et al., "Structure of the SARS-CoV-2 spike receptor-binding domain bound to the ACE2 receptor," Nature, vol. 581, no. 7807, pp. 215220, 2020, doi: 10.1038/s41586-020-2180-5.

[15] Y. Renhong, Z. Yuanyuan, L. Yaning, X. Lu, G. Yingying, and Z. Qiang, "Structural basis for the recognition of SARS-CoV-2 by full-length human ACE2," Science (80-. )., vol. 367, no. 6485, pp. 1444-1448, 2020.

[16]J. Shang et al., "Structural basis of receptor recognition by SARS-CoV-2," Nature, vol. 581, no. 7807, pp. 221-224, 2020, doi: $10.1038 / \mathrm{s} 41586-020-2179-\mathrm{y}$.

[17] A. C. Walls, Y. J. Park, M. A. Tortorici, A. Wall, A. T. McGuire, and D. Veesler, "Structure, Function, and Antigenicity of the SARS-CoV-2 Spike Glycoprotein," Cell, vol. 181, no. 2, pp. 281-292.e6, 2020, doi: 10.1016/j.cell.2020.02.058.

[18] D. Wrapp et al., "Cryo-EM structure of the 2019nCoV spike in the prefusion conformation," Science (80-. )., vol. 367, no. 6483, pp. 12601263, 2020, doi: 10.1126/science.aax0902.

[19] S. Legrand et al., "GPU-Accelerated Drug Discovery with Docking on the Summit Supercomputer: Porting, Optimization, and Application to COVID-19 Research," Proc. 11th ACM Int. Conf. Bioinformatics, Comput. Biol. Heal. Informatics, BCB 2020, 2020, doi: $10.1145 / 3388440.3412472$.

[20] H. Li et al., "Drug design targeting protein-protein interactions (PPIs) using multiple ligand simultaneous docking (MLSD) and drug repositioning: Discovery of raloxifene and bazedoxifene as novel inhibitors of IL-6/GP130 interface," J. Med. Chem., vol. 57, no. 3, pp. 632641, 2014, doi: 10.1021/jm401144z.

[21] C. Granchi et al., "Development and validation of a docking-based virtual screening platform for the identification of new lactate dehydrogenase inhibitors," Molecules, vol. 20, no. 5, pp. 87728790, 2015, doi: 10.3390/molecules20058772.

[22]Q. Wang et al., "Structural Basis for RNA Replication by the SARS-CoV-2 Polymerase," Cell, vol. 182, no. 2, pp. 417-428.e13, 2020, doi: 10.1016/j.cell.2020.05.034.

[23]L. P. Prasad Patro and T. Rathinavelan, "STRIDER: Steric hindrance estimator," bioRxiv, p. 2020.02.07.931550, Jan. 2020, doi: 10.1101/2020.02.07.931550.

[24] T. M. Dhorajiwala, S. T. Halder, and L. Samant, "Comparative in silico molecular docking analysis of 1-threonine-3-dehydrogenase, a protein target against African trypanosomiasis using selected phytochemicals," J. Appl. Biotechnol. Reports, vol. 6, no. 3, pp. 101-108, 2019, doi: 10.29252/JABR.06.03.04. 